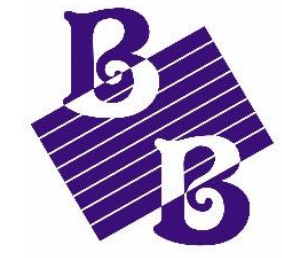

BioBacta

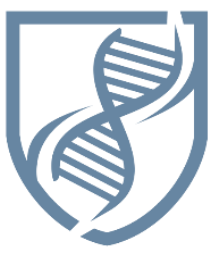

Journal of Bioscience and Applied Research

www.jbaar.org

\title{
Improving Intravenous Medication Administration and Reducing Medication Errors Among Critical Care Nurses at Jordan University Hospital
}

\author{
Mahmoud Abdul Hameed Shahin \\ Al-Ghad International Colleges for Applied Medical Sciences, KSA \\ DOI: 10.21608/jbaar.2019.147401
}

*Corresponding author:

Dr. Mahmoud Abdul Hameed Shahin, RN, MSN, Ph.D. in Critical Care Nursing,

Assistant Professor at Al-Ghad International Colleges for Applied Medical Sciences, KSA

Email: Mahmood81us@yahoo.com, Mshahin@gc.edu.sa Mob: +966507453387

Received date: May 20, 2019. Accepted: August 10, 2019, Published: August 16, 2019

\section{Abstract:}

Background: Medication errors represent a serious problem in the hospital setting and remain a challenge to navigate among hospitalized patients in all departments. Mistakes in medication administration are considered a significant issue that threatens a patient's safety and may increase their hospital stay, treatment costs, and mortality rate. Medication errors commonly committed by nurses may include medication preparation or administration errors, which are associated with the highest risk areas in nursing practice. Methodology: A pretest-posttest, quasi-experimental, the observational design was used. Convenience sampling was employed to include all intravenous medication errors committed by nurses in three ICUs of Jordan University Hospital (pretest: 236 errors and post-test: 68 errors, respectively). A designed incident report was used for data collection. Data collection was carried out simultaneously in the three ICUs during nurses' preparation and administration of intravenous medications over two months for pretest and posttest data (May and June 2018). A tailored evidencedbased educational program designed using Phillips's Manual of I. V. Therapeutics: Evidence-based Practice for Infusion Therapy was furnished to all registered nurses utilizing structured classroom lectures and on-the-job training; moreover, educational medals of common medications and illustration posters were used as additional reminders.Results and Conclusion: More than half of nurses were females and held bachelor's degrees. Half of the observed medication errors were identified in the surgical ICU. Intravenous medication errors observed during the day shift were significantly higher in number than those in the night shift. A significant reduction in the number of medication errors was noted after the implementation of a bundle of interventions (i.e., there was a reduction from 236 errors to 68 errors). Giving (1) an omeprazole push and then (2) administering vancomycin rapidly thereafter, followed by (3) administering omeprazole at the wrong time, were the three most observed medication 
errors in the ICUs. Most medication errors were not reported officially using incident reports. Based on the category of the intravenous medication error, 'wrong medication rate' followed by 'wrong medication time', and then 'mixing the medication with another drug' were the most prominent errors noticed. The rate of reported medication errors was significantly higher after program implementation. An ongoing surveillance system is required to monitor intravenous medication errors and to know the causes to find a solution to further decrease them and their consequences. Also, all nurses should receive an intensive specialized evidence-based educational program about medication handling, utilizing clinical training, and frequent reminding.

Keywords: Intravenous medications, medication errors, critical care nurses, intensive care units (ICUs).

\section{Introduction}

A medication error is defined as 'any preventable event that may cause or lead to inappropriate medication use or patient harm while the medication is in the control of the health care professional, patient, or consumer. Such events may be related to professional practice, health care products, procedures, and systems, including prescribing, order communication, product labeling, packaging, nomenclature, compounding, dispensing, distribution, administration, education, monitoring, and use, irrespective of whether such errors lead to adverse consequences or not'(Medication Error Reporting and Prevention, 2015).

Medication errors occur when health care providers either choose an unsuitable method of care or choose the correct solution of care but execute it erroneously. Medication errors are often described as human errors in healthcare (WHO, 2016). A medication error is a serious problem in the hospital setting and remains a significant item of concern among hospitalized patients in all departments (Jennane et al., 2011). Prescribing errors may be associated with the incorrect selection of a certain drug or drug regimen for a patient. Such errors may include discrepancies in dosage or indication or the prescribing of a contraindicated drug. Lack of knowledge of the prescribed medication (in terms of its recommended dose, clinical use, and the patient's clinical condition) commonly contributes to prescription errors (Shahin, 2018).
Dispensing errors occur when the pharmacist dispenses medication despite the presence of prescription errors. Dispensing errors include those involving the wrong drug, wrong patient, and wrong dose (Lan, Zhu, \& Zhou, 2014). Administration errors occur while giving the medication to the patient. Drug administration has long been associated with one of the highest risk areas in nursing practice, with the ' 12 rights' (i.e., giving the right dose of the right drug to the right patient at the right time by the right route using the right preparation, the right assessment, and the right evaluation with the right documentation and the right approach while respecting the patient's right to know the drug and their right to refuse it) being the cornerstone of nursing education. Drug administration errors largely involve errors of omission, where the drug is not administered for a variety of reasons (Shahin, 2018).

\section{The significance of the study}

Medication errors are considered a significant issue that can affect patients' safety and increase the length of the hospital stay, costs, and patient mortality rate. Those consequences may result in the loss of the patients' and their family members' trust in the health care system as well as decreased satisfaction (Miller, 2018). Generally, there is a lack of studies about intravenous medication errors in Jordan; furthermore, few studies have been conducted to help with reducing intravenous medication errors and improving nurses' 
practice in this regard among the Jordanian hospitals (Mrayyan, 2012; Salami et al., 2019; Shahin, 2018; Sulaiman, 2014; Vrbnjak, Denieffe, O'Gorman, \& Pajnkihar, 2016). By conducting this study, the level of nurses' knowledge regarding intravenous medication handling is expected to increase, which most likely will lead to better performance with and handling of drugs and reduced incidents of medication errors in the intensive care units, thus increasing patients' safety and improving their health conditions.

\section{Literature review}

\section{Incidence of medication errors}

In the late 1980s and early 1990s, medication error rates were found to affect between $5 \%$ and $18 \%$ of all drugs administered (Stewart, Naismith, Biro, Marinos, \& Woonton, 1991). Currently, the incidence of medication errors is greatly underestimated and underreported (Bjorksten, Bergqvist, Andersen-Karlsson, Benson, \& Ulfvarson, 2016).

As the world's population, especially the aged population, continues to increase and the consequences of chronic health problems grow, a higher number of medication errors are expected to occur (Tobias, Yadav, Gupta, \& Jain, 2013). Studies of medication errors were conducted worldwide with different designs and methodologies; moreover, the definitions of medication errors resulted in differences in the reported errors $(2 \%-14 \%)$ for inpatients at the included hospitals (Dirik, Samur, Seren Intepeler, \& Hewison, 2019). In Jordan, medication errors are serious, growing, and requiring more attention to all types of hospitals. However, few studies have been conducted in the last few years regarding the reported incidence of medication errors (Mrayyan, 2012; Salami et al., 2019; Shahin, 2018; Sulaiman, 2014; Vrbnjak et al., 2016).

Across hospitals in Jordan, there was no difference found regarding the rate of medication errors, but the reported incidence of medication errors in private hospitals seemed to be more than that in teaching and governmental hospitals (Mrayyan, Shishani, \& AlFaouri, 2007). Moreover, a high rate of medication errors occurred in intensive care units (ICUs) (36\%) and almost $33 \%$ occurred on the floors. Although the picture of medication errors in Jordan is not complete, the average number of committed and reported medication errors by nurses was $42.1 \%$, which is the highest among all other professions in the Jordanian hospitals (Mrayyan et al., 2007). Since nurses make up the largest portion of health care providers and medication errors are mostly proportional to the number of nurses, there should be a greater focus on educating the nursing staff to identify the causes of medication errors and work to overcome them.

\section{Impact of medication errors}

Medication errors affect patient safety and costs in hospitals; specifically, their costs have been estimated at between 17 and 29 billion dollars per year in hospitals, which includes the expense of the additional care needed to correct those errors, lost income, and disability care (Di Simone et al., 2016). Medication errors have a direct effect on the affected patients and their families such as longer hospital stays, increased costs, and higher rates of patient mortality. These effects result in a loss of trust in the health care system among patients and diminished satisfaction in both patients and health care professionals. Medication errors are the second cause for lawsuits involving nurses in the United States and the most common reason for removal from the nursing council register in the United Kingdom (Kohn, Corrigan, \& Donaldson, 2000). Therefore, the potential for a medication error in the medication administration stage is a problem of concern to the nursing staff.

\section{Causes of medication errors}

Many studies have been conducted globally to identify the causes of medication errors in hospitals, 
and the causes identified were different based on whether the cause was related to the health care system or health care providers themselves. Based on the literature and concerning these two categories, the causes of medication errors were summarized, not exclusively, as the following: health care system (e.g., poor work environment, policies and procedures, nursing shortage, and workload) and health care providers (e.g., nursing educational level and experience, nursing knowledge, medication knowledge deficiency, confusion over medication names and packaging, poor calculation skills, medication preparation related factors, communication problems, and illegible handwriting) (Sulaiman, 2014).

A lack of nurses' knowledge about a patient's diagnosis, medication names, purposes, and/or correct administration of the medications was the most significant contributing factor to medication errors (Lan et al., 2014). Good practices and adequate knowledge of medications will assist nurses in administering medications effectively and correctly. Therefore, nurses require essential knowledge in pharmacology and competency in medication administration to help eradicate any potential for error (Keane, 2014).

Limited studies were conducted to date to identify the impact of on-the-job nursing education on reducing medication errors committed by nurses at hospitals, with most of these studies finding a significant effect of on-site educational programs provided to nurses regarding their medication handling practices and the reporting of medication errors $(\mathrm{Xu}, \mathrm{Li}, \mathrm{Ye}, \& \mathrm{Lu}$, 2014). Further studies are needed to focus on the impact of educational programs on the medication handling safety protocols practiced by nurses to support the results of previous studies, especially in Jordan and the larger region of the Middle East.

Aim of this study
The study aimed to identify the types and number of intravenous medication errors committed by nurses in the ICUs and to evaluate the effect of implementing a bundle of instructional interventions on the frequency of these medication errors at Jordan University Hospital.

\section{Theoretical framework}

Since the current study begins with an assessment of the status quo and nurses' current understanding of medications handling practices before moving to the determination of the most common medication errors commenced by nurses during preparation and administration and the creation of a plan to overcome the problem and improve the situation based on the preliminary assessment data, then finally to the actual implementation of the suggested remedies or solutions and the evaluation of the initiative's performance to assure an effective improvement program is in place, it was deemed convenient to adopt the nursing process as a theoretical framework for the current study. The nursing process is based on a nursing theory developed by Ida Jean Orlando in the late 1950s and consists of five steps: assessment, diagnosis, planning, implementation, and evaluation (Carpenito-Moyet, 2006).

Assessment, the first stage, is where the nurse should carry out a complete and holistic nursing assessment of every patient's or community's needs, regardless of the reason for the encounter. Here, the researcher initially assessed nurses' performance regarding intravenous medication handling and administration practices. Nursing diagnosis involves the analysis of the data collected to identify the medication errors performed by critical care nurses and the types of deficits. Planning involves setting priorities, establishing goals, identifying desired outcomes, and determining specific interventions. The researcher planned and constructed a poster, educational program, and instructional medal about 
medication handling based on nurses' predetermined needs and priorities. The implementation stage involves putting the nursing care plan into action; for this, the researcher utilized the posters and medals and introduced the tailored educational program about medication administration based on the predetermined plan. Finally, evaluation helps to determine if goals are met or not. In this study, for this stage, the researcher evaluated the effectiveness of the interventions on medication handling practices by nurses and the frequency of medication errors.

\section{Methodology}

\section{$\underline{\text { Research design }}$}

A pretest-posttest quasi-experimental, observational design was utilized in this research (design: $\mathrm{O} 1 \times \mathrm{O} 2$ ).

\section{Sampling}

Convenience sampling was employed as a sampling methodology. All accessible intravenous medication errors committed by critical care nurses were included in the study sample $(n=304)$. A total of 236 medication errors were included in the pretest stage of the study, while 68 medication errors were included in the posttest stage.

\section{Setting}

The study was conducted at the Jordan University Hospital, specifically in the following three ICUs: the medical ICU (MICU), the surgical ICU (SICU), and the neurology ICU (NICU).

\section{Data collection tool}

Data collection was carried out using a designed incident report (i.e., medication errors observational checklist). This tool was developed by the researcher utilizing the incident report form available already at the Jordan University Hospital to determine the type and details of the intravenous medication errors. The tool also requested sociodemographic data for the registered nurse who committed the medication error.
The tool was piloted in the reporting of six medication errors before being used officially for data collection to test its clarity and efficiency. Some recommended modifications were made at this point accordingly to develop the final format of the observational checklist. Those six medication errors were then excluded from the pretest sample set. Content validity analysis of the tool was done by taking the opinions of three experts on medication administration (a clinical pharmacist, a charge nurse of the ICU, and a clinical instructor). Interrater reliability was also found to be acceptable for the tool (i.e., Cronbach's coefficient alpha was satisfactory at 0.845 ).

\section{Procedures}

The data collection was carried out simultaneously among the three ICUs using direct observations of all registered nurses during their preparation and administration of intravenous medications over both shifts (Day and Night). The researcher and seven trained data collectors monitored and documented intravenous medication errors committed by nurses in the units over two weeks as a pretest evaluation and for the same period as a post-test evaluation (May and June 2018).

\section{Interventions}

Based on the reported intravenous medication administration errors, a tailored educational program was designed by the researcher using the "Phillips's Manual of I. V. Therapeutics: Evidence-based Practice for Infusion Therapy" textbook as a reference (Gorski, 2018). All registered nurses at the three ICUs were exposed to an intensive educational program about intravenous medication handling that incorporated structured classroom lectures and on-the-job training.

As a reminder, each nurse was given an educational medal, containing some cards, designed by the researcher to give drugs' information and summarize the most common intravenous medication administration errors encountered by nurses in the 
hospitals based on the pretest findings; moreover, a poster displaying the phrase 'I am sick enough, please do not hurt me', was designed and put as a reminder in the included units to focus on the effects of drugs on body organs and the impact of medication errors on patients' health. Posttest data were gathered after the provision of the educational program and other instructional measures to assess the number and types of intravenous medication administration errors and the changes that occurred as a result of the interventions provided.

\section{Ethical considerations}

After submitting the proposal, official permission to move forward with the present study was obtained from the institutional review board of the Jordan University Hospital. The purpose of the study and the procedure was explained to the participants; moreover, participation in this study was voluntary. No harm was expected to come to patients or nurses and all information was kept confidential.

After reading a document providing complete clarification of the purpose and nature of the study, verbal consent was obtained from each registered nurse in the three selected ICUs to be monitored for intravenous medication handling and reported on as well. All nurses were assured that participation in this study was voluntary, anonymous, and confidential and that their data were to be protected by the allocation of a code number for each observational checklist. Also, no harm was expected to occur due to the implementation of this study. The results of the study were submitted to the education department manager at Jordan University Hospital.

\section{Statistical design}

Collected data were extracted, tabulated, scored, and analyzed. Descriptive and inferential statistics were carried out. The collected data were analyzed using Statistical Package for the Social Sciences version 20 computer program (IBM Corp., Armonk, NY, USA) to determine the medication errors and demographics of the surveyed nurses (Leech, Barrett, \& Morgan, 2014). Data are presented in both descriptive forms [means, standard deviations (SDs), t-test, etc.] as well as correlation tests ( $\mathrm{p}$-value $\leq 0.05$ ).

\section{Results}

For the sociodemographic data of the nurses who committed medication errors in the three studied ICUs, it was found that the mean age of the nurses was 30.9 years, with 7.74 average years of health care work experience. More than half of the nurses were female (63.2\%) and most of them held bachelor's degrees (90.8\%). Additionally, $82.2 \%$ of nurses interviewed due to committing medication errors reported that they had received previous education about medication handling and administration; on the other hand, none of them reported that they had participated in a research project related to medications previously (Table 1). 
Table 1: Sociodemographic data of nurses who committed medication errors

\begin{tabular}{|l|c|c|c|c|}
\hline Sociodemographic data & Min & Max & $\begin{array}{c}\text { Mean (n } \\
=304)\end{array}$ & SD \\
\hline Age of nurses (years) & 26 & 38 & 30.89 & 4.074 \\
\hline Years of experience & 4 & 11 & 7.74 & 2.971 \\
\hline Sociodemographic data & & $\begin{array}{c}\text { Frequency } \\
\text { (n =304) }\end{array}$ & Percent \\
\hline \multirow{2}{*}{ Gender } & Male & 112 & 36.8 \\
\hline \multirow{2}{*}{ Educational level } & Female & 192 & 63.2 \\
\hline Received previous education about medication & Bachelor & 276 & 90.8 \\
\cline { 2 - 4 } \\
handling & Postgraduate & 28 & 9.2 \\
\cline { 2 - 4 } $\begin{array}{l}\text { Previously participated in a research project about } \\
\text { medications }\end{array}$ & Yes & 250 & 82.2 \\
\cline { 2 - 4 } & No & 54 & 17.8 \\
\hline
\end{tabular}

As seen in Table 2, the number of medication errors that occurred during the pretest observation was 236 versus the 68 that were observed after the implementation of the interventions bundle. Thus, a significant reduction in the number of medication errors was noted after the implementation of a bundle of interventions $(\mathrm{p}=0.000)$ (Table 3$)$. This result is confirmed in Table 3 by applying a one-sample test to assess the difference in the medication error frequency before and after the implementation of the instructional program. The frequency of medication errors was higher during the day shift in comparison with during the night shift (61.8\% and $38.2 \%$, respectively). In the distribution of the committed medication errors, almost half of medication errors were observed in the SICU (50.7\%), followed by $29.6 \%$ observed in the MICU and $19.6 \%$ in the NICU (Table 2).

Table 2: Medication errors observed in the ICUs

\begin{tabular}{|l|c|c|c|}
\hline Medication error observations & & Frequency $(\mathrm{n}=304)$ & Percent \\
\hline Medication errors & Pre-test & 236 & 77.6 \\
\cline { 2 - 4 } & Post-test & 68 & 22.4 \\
\hline \multirow{2}{*}{ The shift of medication errors } & Day & 188 & 61.8 \\
\cline { 2 - 4 } & Night & 116 & 38.2 \\
\hline \multirow{2}{*}{ The unit of medication errors } & SICU & 154 & 50.7 \\
\cline { 2 - 4 } & MICU & 90 & 29.6 \\
\cline { 2 - 4 } & NICU & 60 & 19.7 \\
\hline
\end{tabular}

Table 3: One-sample t-test of the difference between pre and post-test medication errors number

\begin{tabular}{|c|c|c|c|c|c|c|}
\hline & \multicolumn{6}{|c|}{ Test value $=0$} \\
\hline & \multirow[t]{2}{*}{$\mathrm{t}$} & \multirow[t]{2}{*}{ df } & \multirow[t]{2}{*}{$\begin{array}{l}\text { Sig. (two- } \\
\text { tailed) }\end{array}$} & \multirow[t]{2}{*}{$\begin{array}{c}\text { Mean } \\
\text { difference }\end{array}$} & \multicolumn{2}{|c|}{$\begin{array}{c}95 \% \text { confidence interval of } \\
\text { the difference }\end{array}$} \\
\hline & & & & & Lower & Upper \\
\hline $\begin{array}{l}\text { Pre- or } \\
\text { Posttest error }\end{array}$ & 51.12 & 303 & 0.000 & 1.224 & 1.18 & 1.27 \\
\hline
\end{tabular}


In Table 4 and during the observations, the majority of intravenous medication errors were noted as (1) giving an omeprazole push and then (2) giving Vancomycin rapidly (in < 30 minutes) and (3) giving omeprazole at the wrong time $(17.8 \%, 16.4 \%, 11.8 \%$ respectively). Oppositely, giving vancomycin at 12:00 noon instead of 2:00 pm, administering a tinam push, giving an epanutin push, mixing perfalgan and meropenem, mixing tavanic and insulin infusion, mixing tinam and fluconazole, and mixing perfelgan and hydrocortisone were similarly the lowest observed medication errors committed by nurses (1.3\% each). After conducting further follow-up of the noted medication errors, unexpectedly, it was found that most medication errors were not reported officially using incident reports (82.9\%; n=304; Table 4).

Table 4: Description of medication errors

\begin{tabular}{|c|c|c|c|}
\hline \multicolumn{2}{|c|}{ Medication errors } & Frequency & Percent \\
\hline \multirow{20}{*}{$\begin{array}{c}\text { Incident } \\
\text { Description }\end{array}$} & Omeprazole push & 54 & 17.8 \\
\hline & Vancomycin within 30 minutes & 50 & 16.4 \\
\hline & Omeprazole wrong time & 36 & 11.8 \\
\hline & Tazocin wrong time & 24 & 7.9 \\
\hline & Lasix push & 20 & 6.6 \\
\hline & Tavanic running & 20 & 6.6 \\
\hline & Tazocin $4.5 \mathrm{~g}$ push & 16 & 5.3 \\
\hline & Perfalgan + tinam & 16 & 5.3 \\
\hline & KCL+ noradrenaline & 12 & 3.9 \\
\hline & Two vasopressors in the same line & 12 & 3.9 \\
\hline & Perfalgan + rocephin & 8 & 2.6 \\
\hline & Rocephin wrong time & 8 & 2.6 \\
\hline & $\begin{array}{l}\text { Vancomycin at } 12: 00 \text { noon instead of } \\
2: 00 \mathrm{pm}\end{array}$ & 4 & 1.3 \\
\hline & Tinam push & 4 & 1.3 \\
\hline & Epanutin push & 4 & 1.3 \\
\hline & Perfalgan + meropenem & 4 & 1.3 \\
\hline & Tavanic + insulin infusion & 4 & 1.3 \\
\hline & Tinam + fluconazole & 4 & 1.3 \\
\hline & Perfelgan + hydrocortisone & 4 & 1.3 \\
\hline & Total & 304 & 100.0 \\
\hline \multirow{3}{*}{$\begin{array}{l}\text { The incident } \\
\text { was reported }\end{array}$} & No & 252 & 82.9 \\
\hline & Yes & 52 & 17.1 \\
\hline & Total & 304 & 100.0 \\
\hline
\end{tabular}


When classifying the medication errors committed followed by 'the wrong medication time' and then by critical care nurses into categories, it was found fixing the medication with another drug' $(56.6 \%$, that 'the wrong medication rate' was the dominant $22.4 \%$, and $21.1 \%$, respectively; Figure 1 ). category of medication administration errors

Figure 1: Categories of medication errors

\section{Categories of Medication Errors}

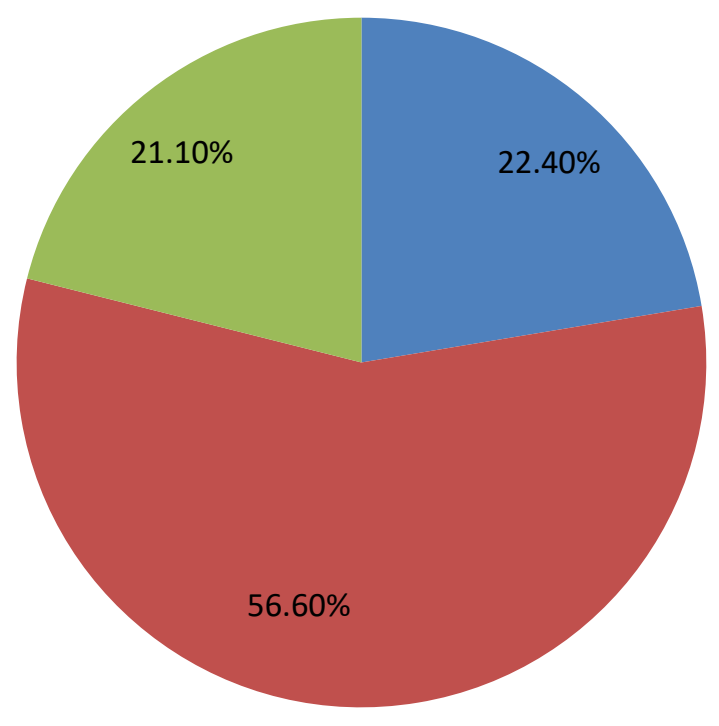

Wrong Time

Wrong Rate

Mixing with other drug

Table 5 illustrated that incident reports were in $9.32 \%$ of medication error cases in the initial written for $44.12 \%$ of the medication errors assessment stage before the delivery of the observed after implementing the bundle of educational program.

interventions, while incidents were reported only

Table 5: Cross-tabulation of reported incidents pre-and posttest

\begin{tabular}{|lc|c|c|c|}
\hline \multirow{2}{*}{} & & \multicolumn{2}{|c|}{ Pre- or posttest error } & \multirow{2}{*}{ Total } \\
\cline { 3 - 4 } & & Pretest & Posttest & \\
\hline The incident was & Yes & $22(9.32 \%)$ & $30(44.12 \%)$ & $52(17.1 \%)$ \\
reported & No & $214(90.68 \%)$ & $38(55.88 \%)$ & $252(82.9 \%)$ \\
Total & & $236(100 \%)$ & $68(100 \%)$ & $304(100 \%)$ \\
\hline
\end{tabular}


Table 6 shows that the number of medication errors reported formally in the hospital was the highest in the MICU, followed by the SICU, whereas the reporting was extremely low in the NICU $(22.2 \%, 19.5 \%$, and $3.33 \%$, respectively).

Table 6: Cross-tabulation of reported incidents and departments

\begin{tabular}{|lc|c|c|c|c|}
\hline & & \multicolumn{3}{|c|}{ Department } & \multirow{2}{*}{ Total } \\
\cline { 3 - 5 } & & SICU & MICU & NICU & \\
\hline The incident was & Yes & $30(19.5 \%)$ & $20(22.2 \%)$ & $2(3.33 \%)$ & $52(17.1 \%)$ \\
reported & No & $124(80.5 \%)$ & $70(77.8 \%)$ & $58(96.67 \%)$ & $252(82.9 \%)$ \\
Total & & $154(100 \%)$ & $90(100 \%)$ & $60(100 \%)$ & $304(100 \%)$ \\
\hline
\end{tabular}

Table 7 represents the statistics about the frequency of medication errors per category before and after the application of the bundle of interventions. The 'wrong time'-associated errors constituted almost $65 \%$ of observed medication errors that occurred after the interventions, while they were responsible for around $10 \%$ of medication errors noted before any intervention. The 'wrong rate' errors constituted about $30 \%$ of medication errors in the posttest stage but accounted for about $65 \%$ of medication errors in the pretest stage. The medication errors related to mixing medications with another drug happened only in 5.88\% of observed medication errors in the posttest stage as compared with $25.42 \%$ in the pretest stage.

Table 7: Medication error category cross-tabulation with pre-or posttest

\begin{tabular}{|l|c|c|c|}
\hline Categories of medication errors & \multicolumn{2}{|c|}{ Pre- or posttest error } & \multirow{2}{*}{ Total } \\
\cline { 2 - 3 } & Pretest & Posttest & \\
\hline Wrong time & $24(10.17 \%)$ & $44(64.71 \%)$ & $68(22.37 \%)$ \\
Wrong rate & $152(64.41 \%)$ & $20(29.41 \%)$ & $172(56.58 \%)$ \\
Mixing with another drug & $60(25.42 \%)$ & $4(5.88 \%)$ & $64(21.05 \%)$ \\
Total & $236(100 \%)$ & $68(100 \%)$ & $304(100 \%)$ \\
\hline
\end{tabular}

\section{Discussion}

These study findings reflect that the experience of nurses in the ICUs of Jordan University Hospital was relatively long and ranged from four to 11 years (mean: 7.74, SD:2.97); moreover, females generally were the most predominant gender. This was congruent with the general experience of nurses at the Jordan University Hospital and that in many previous studies (Abu Raddaha et al., 2012; Mrayyan, 2012; Shahin, 2018). Most nurses who committed medication errors reported that they had attended previous education sessions about medication handling; however, they expressed that the educational programs were either short and not specialized or conducted without clinical training and not effective. Additionally, all nurses reported that they had no previous research project experience associated with medication handling in hospitals.

The frequency of medication errors dropped significantly after implementing the interventions in this study 
( $p=0.000)$. This is strong proof of the positive impact of the bundle of interventions applied and that providing an extensive and specialized evidence-based educational program to nurses utilizing clinical training and some technical reminders or follow-up is likely to have a remarkable effect on reducing intravenous medication errors and improving drugs' handling in the ICUs.

Intravenous medication errors observed among nurses during the day shift were significantly higher in number than those for the night shift. The higher rate of medication errors may relate to the high workload and fatigue of nurses in the day shift, disturbance by nursing managers and supervisor's visits, and confusion by physicians' orders and rounds. The findings were congruent with those of a previous study by Shahin et al. (2018) and a systematic review conducted by Karavasiliadou and Athanasakis (2014) (Karavasiliadou \& Athanasakis, 2014; Shahin et al., 2018; Tang, Sheu, Yu, Wei, \& Chen, 2007). On the other hand, these results contradicted those of a study that concluded that the night shift medication error rate was consistently higher than that for the day shift (Hughes, 2016).

Regarding the intravenous medication error description, the finding reflected that giving omeprazole push, fast vancomycin administration, giving omeprazole at the wrong time, and giving tazocin at the wrong time were the most frequently observed medication administration errors committed by nurses in the ICUs. Nurses had unclear knowledge and misconceptions about those drugs. They thought that their practices regarding intravenous drug administration did not affect the health of their patients or even on drugs' action or effectiveness. The findings in Jordan were different from those of a study conducted in Ethiopia, which found that the top five drugs with high error rates were, in order of highest to lowest, cimetidine, clopidogrel, omeprazole, dopamine, and tramadol. More than one-third of the total errors recorded occurred involving these five drugs (Sada, Melkie, \& Shibeshi, 2015).

Intravenous medication errors were not reported in most of the cases, which reflected the intentional hiding of these events or the unawareness about the need to make an official report of such an event. This trend was similarly found in many other studies that showed that medication error reporting is still significantly low. The rate of reporting medication errors among nurses was far less than the actual medication errors they had made (Bayazidi, Zarezadeh, Zamanzadeh, \& Parvan, 2012; Shahin, 2018; Vrbnjak et al., 2016). After exposing critical care nurses to interventions and educational programs, the reporting of medication errors rose more than four times. This reflects the misconception of nurses about the reporting of medication errors, including the importance and consequences; moreover, it reflects the positive effect of such instructional interventions in raising awareness among nurses about the reporting of incidents. Similar results were reflected regarding improving medication error reporting in many previous studies conducted around the world (Alsulami, Conroy, \& Choonara, 2013; Bairami \&Taleghani, 2016; Di Simone et al., 2016; Keane, 2014; Lee, 2017; Westbrook, Rob, Woods, \& Parry, 2011).

Intravenous medication administration errors were frequent among ICU patients. 'Wrong medication rate' was the most frequent error, followed by "wrong medication administration time', and then 'errors of mixing the medication with another drug'. In a similar study from Australia, 'wrong medication rate' was the most frequent error and accounted for the majority of serious errors recorded. 'The wrong drug rate' followed by 'the wrong volume' and then 'the wrong mixture' were the most common errors noticed in the chosen hospitals (Westbrook et al., 2011). Upon exposing nurses to the instructional program, it was clear that the 
number of medication errors dropped significantly, especially for the 'wrong rate' errors and 'drug mixing' errors. These types of medication errors were mainly attributed to nurses' misconceptions and malpractice; thus, they can be reduced easily by nursing education.

\section{Summary}

Intravenous medication errors are one of the most common threats to patients' safety in the ICU. However, though they are frequently seen, they are usually insufficiently reported. Furthermore, even with lengthy experience periods among critical care nurses, the rates of medication errors stay dangerously high. Although nurses generally may be exposed to some sort of education about medication handling, they still need to receive an intensive specialized evidence-based educational program about medication errors with the utilization of clinical training and time-to-time reminders. Providing evidence-based educational programs to staff nurses in the intensive care units with the inclusion of on-the-job training, follow-up, and reminders have a remarkable effect in reducing intravenous medication errors in the ICUs. Greater medication errors were detected during day shifts as compared with during night shifts due to various reasons, such as the high workload, multitasking, and the interruption and disturbance of nurses in the day shifts.

Nurses in the ICU generally have misconceptions about medication handling, which certainly led to more medication errors. Intravenous medication error reporting was considerably low, which may reflect either intentional under-reporting or the low awareness of nurses about the necessity of medication error reporting in the critical care setting. The rate of intravenous medication error reporting improved significantly after exposing nurses to the educational programs, which reflects the constructive effect of such instructional interventions in raising the level of awareness among nurses about incident reporting.
The most prominent intravenous medication errors detected in the surveyed ICUs were 'wrong medication administration rate' followed by 'wrong medication administration time' and 'errors of mixing the medication with another drug'. Medication errors associated with nurses' misconceptions and malpractice, such as 'wrong administration rate' and 'drug mixing', were the most improved upon exposure to drug-handling instructional programs.

\section{Recommendations}

An ongoing surveillance system in the hospitals is required to monitor intravenous medication handling to detect errors in the prescribing, preparation, and administration of drugs by staff. Identifying medication errors can help to elucidate the causes of errors and thus find a solution to decrease both their frequency and consequences. The rate of intravenous medication error reporting in Jordanian hospitals is still extremely low. All clinical nurses in the intensive care units (both junior and senior nurses) should undergo intensive specialized evidence-based education about medication handling that incorporates clinical training and frequent reminding. Such education programs have been proven to have a notable effect in reducing medication errors in ICUs. Nurses' misconceptions and lack of understanding of proper intravenous medication handling lead to a higher rate of medication errors in ICUs; therefore, as nurses' awareness about medication errors and drug handling improves, the rate of medication error reporting is expected to increase as well.

Greater intravenous medication errors were detected during the day shift in comparison with during the night shift, which may reflect the high workload and the more frequent interruption of nursing work during the former; thus, more interventions should be enacted to help reduce medication errors during the day shifts, taking into consideration all possible causes behind their occurrence. The most prominent intravenous 
medication errors detected in the surveyed ICUs were 'wrong medication administration rate' followed by 'wrong medication administration time' and then 'errors of mixing the medication with another drug'; based on that, tailored educational programs about medication handling should be constructed to reduce medication errors encountered in the ICUs pertinent to the frequency of medication error category.

\section{Limitations of the study}

Randomization was the main limitation of the current study, additionally; the number of cases in this study may also inhibit the generalizability of the findings. A further qualitative study might provide additional in-depth data and strengthen the findings of this study.

\section{Acknowledgments}

The author is indebted to the administration staff and nurses at Jordan University Hospital for their cooperation and assistance in this study. This acknowledgment is extended specifically to Mrs. Hanadi Husni Al-Abed and her team for their dedicated efforts in data collection in the ICUs and their continual support.

\section{Declaration}

The author declares that no conflicts of interest about this research exist.

\section{References}

Abu Raddaha, A. H., Alasad, J., Albikawi, Z. F., Batarseh, K. S., Realat, E. A., Saleh, A. A., \& Froelicher, E. S. (2012). Jordanian nurses' job satisfaction and intention to quit. Leadership in Health Services, 25(3), 216-231.

Alsulami, Z., Conroy, S., \& Choonara, I. (2013). Medication errors in the Middle East countries: a systematic review of the literature. Eur J Clin Pharmacol, 69(4), 995-1008. DOI: $10.1007 / \mathrm{s} 00228-012-1435-\mathrm{y}$
Bairami, F., \& Taleghani, Y. M. (2016). Improving medical error reporting: A successful experience from Iran. Iranian journal of public health, 45(5), 713-714.

Bayazidi, S., Zarezadeh, Y., Zamanzadeh, V., \& Parvan, K. (2012). Medication error reporting rate and its barriers and facilitators among nurses. Journal of caring sciences, 1(4), 231.

Bjorksten, K. S., Bergqvist, M., Andersen-Karlsson, E., Benson, L., \& Ulfvarson, J. (2016). Medication errors as malpractice-a qualitative content analysis of 585 medication errors by nurses in Sweden. BMC Health Serv Res, 16(1), 431. DOI: 10.1186/s12913-016-1695-9

Carpenito-Moyet, L. J. (2006). Nursing diagnosis: Application to clinical practice: Lippincott Williams \& Wilkins.

Di Simone, E., Tartaglini, D., Fiorini, S., Petriglieri, S., Plocco, C., \& Di Muzio, M. (2016). Medication errors in intensive care units: nurses' training needs. Emerg Nurse, 24(4), 2429. DOI: $10.7748 /$ en.2016.11577

Dirik, H. F., Samur, M., Seren Intepeler, S., \& Hewison, A. (2019). Nurses' identification and reporting of medication errors. J Clin Nurs, 28(5-6), 931-938. DOI: 10.1111/jocn.14716

Gorski, L. A. (2018). Phillips's Manual of IV Therapeutics: Evidence-Based Practice for Infusion Therapy: FA Davis.

Hughes, V. (2016). Is There a Relationship Between Night Shift and Errors? What Nurse Leaders Need to Know. Athens Journal of Health, 3(3), 217-228.

Jennane, N., Madani, N., OuldErrkhis, R., Abidi, K., Khoudri, I., Belayachi, J., . . . Abouqal, R. (2011). Incidence of medication errors in a Moroccan medical intensive care unit. International archives of medicine, 4(1), 32.

Karavasiliadou, S., \& Athanasakis, E. (2014). An inside look into the factors contributing to 
medication errors in the clinical nursing practice. Health Science Journal, 8(1).

Keane, K. (2014). Reducing Medication Errors By Educating Nurses on Bar Code Technology. Medsurg Nurs, 23(5), Suppl 1, 10-11.

Kohn, L. T., Corrigan, J., \& Donaldson, M. S. (2000). To err is human: building a safer health system (Vol. 6): National academy press Washington, DC.

Lan, M. J., Zhu, L. L., \& Zhou, Q. (2014). Medication administration errors made by nurses reflect the level of pharmacy administration and hospital information infrastructure. $J$ Clin Nurs, 23(5-6), 894-895. DOI: 10.1111/jocn. 12495

Lee, E. (2017). Reporting of medication administration errors by nurses in South Korean hospitals. Int J Qual Health Care, 29(5), 728-734. DOI: 10.1093/intqhc/mzx096

Leech, N. L., Barrett, K. C., \& Morgan, G. A. (2014). IBM SPSS for intermediate statistics: Use and interpretation: Routledge.

Medication Error Reporting and PreventionMERP, N. (2015). National Coordinating Council for Medication Error Reporting and Prevention. About Medication Errors: What is a Medication Error.

Miller, K. (2018). Effect of Root Cause Analysis on Pre-Licensure, Senior-Level Nursing Students' Safe Medication Administration Practices.

Mrayyan, M. T. (2012). Reported incidence, causes, and reporting of medication errors in teaching hospitals in Jordan: a comparative study. Contemp Nurse, 41(2), 216-232. DOI: 10.5172/conu.2012.41.2.216

Mrayyan, M. T., Shishani, K., \& AL-FAOURI, I. (2007). Rate, causes, and reporting of medication errors in Jordan: nurses' perspectives. Journal of nursing management, 15(6), 659-670.
Sada, O., Melkie, A., \& Shibeshi, W. (2015). Medication prescribing errors in the medical intensive care unit of Tikur Anbessa Specialized Hospital, Addis Ababa, Ethiopia. $B M C$ research notes, $8(1), 448$.

Salami, I., Subih, M., Darwish, R., Al-Jbarat, M., Saleh, Z., Maharmeh, M., . . . Al-Amer, R. (2019). Medication Administration Errors: Perceptions of Jordanian Nurses. J Nurs Care Qual, $\quad 34(2), \quad$ E7-E12. $\quad$ DOI: 10.1097/NCQ.0000000000000340

Shahin, M., Bakr Al-Waqfi, B., Al-Abed H. (2018). Perception of Medication Errors among Critical Care Nurses in Jordanian Hospitals: Causes and Reporting. International Journal of Current Research, 10(11), 75657-75663. DOI: 10.24941/ijcr.33252.11.2018

Stewart, R., Naismith, N., Biro, J., Marinos, Y., \& Woonton, B. (1991). Establishing the need forward pharmacy: a survey of drug administration and medication errors in a public teaching hospital. Aust J Hosp Pharm, $21,378-383$.

Sulaiman, Z. H. (2014). Detection and Evaluation of Medication errors at. The University of Petra.

Tang, F. I., Sheu, S. J., Yu, S., Wei, I. L., \& Chen, C. H. (2007). Nurses relate the contributing factors involved in medication errors. $J$ Clin Nurs, 16(3), 447-457.

Tobias, J. D., Yadav, G., Gupta, S. K., \& Jain, G. (2013). Medication errors: A matter of serious concern. Anaesth Pain Intensive Care, 17(2), 111-114.

Vrbnjak, D., Denieffe, S., O'Gorman, C., \& Pajnkihar, M. (2016). Barriers to reporting medication errors and near misses among nurses: A systematic review. Int J Nurs Stud, 63, 162178. DOI: 10.1016/j.ijnurstu.2016.08.019

Westbrook, J. I., Rob, M. I., Woods, A., \& Parry, D. (2011). Errors in the administration of intravenous medications in hospital and the 
role of correct procedures and nurse experience. BMJ Qual Saf, 20(12), 1027-1034.

WHO. Medication Errors: Technical serials on Safer Primary Care [Internet]. Geneva: WHO; 2016 [cited 2018 June 26].

Xu, C., Li, G., Ye, N., \& Lu, Y. (2014). An intervention to improve inpatient medication management: a before and after study. Journal of nursing management, 22(3), 286-294. 